\title{
Migration in later life: evidence from the British Household Panel Study
}

\author{
Maria Evandrou, Jane Falkingham, Marcus Green \\ ESRC Centre for Population Change \& Centre for Research on Ageing, University of Southampton
}

\begin{abstract}
This article uses data from the British Household Panel Study over the period $1991-2007$ to examine the factors associated with residential mobility among people aged $\mathbf{5 0}$ and over. In line with earlier research, the likelihood of migrating, that is, changing address, is found to vary according to the demographic and socio-economic characteristics of the older person. Those in late middle age (50-59) and the oldest-old (90 and over) were most likely to move. Migration was also strongly associated with changes in partnership, health and economic status during the last 12 months, highlighting the importance of seeing migration within a life course context with certain life course events such as divorce, widowhood or retirement being important triggers for prompting a move. As divorce and remarriage become more common in later life, 'relationship driven migration' is likely to become more important, adding a new category to the classical typology of later life migration.
\end{abstract}




\section{Contents}

Migration in later life: Evidence from the British Household Panel Study ...................77

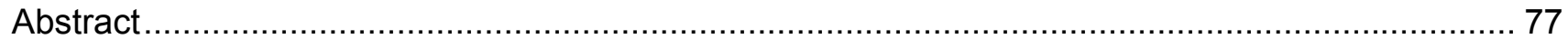

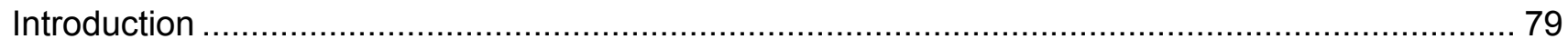

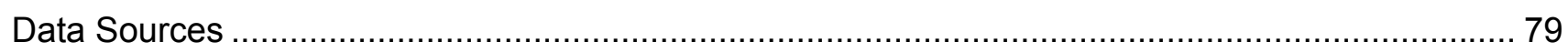

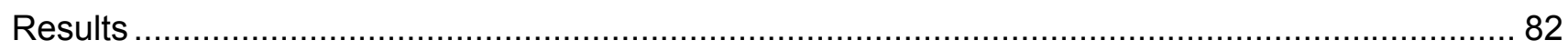

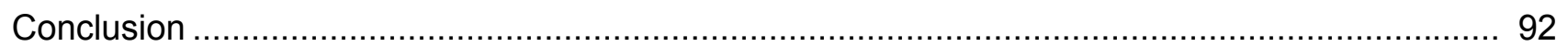

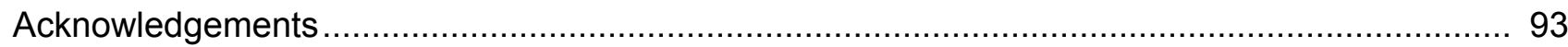

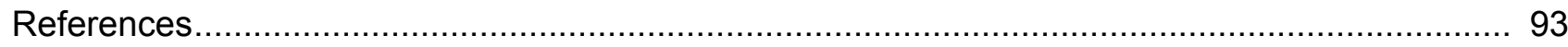




\section{Introduction}

The UK's population is ageing. According to the ONS 2009 mid-year population estimates published in June 2010, 21.3 million people are currently aged 50 and over ${ }^{1}$. A better understanding of the characteristics of this section of the population is critical for the efficient and effective planning of services both by the public and private sector. Most migration studies focus on labour migrants and there is relatively little recent research on older migrants. Much of the existing research on migration in later life has focused on international migration from England and Wales to foreign destinations in retirement, most notably to the countries of southern Europe (Williams et al ${ }^{2}$; King et al ${ }^{3}$; Warnes and Patterson ${ }^{4}$; King et al ${ }^{5}$ ); while more recently Green, Evandrou and Falkingham $(2009)^{6}$ have examined international migration to the UK in later life. However, the vast majority of moves in later life are moves within the UK. The recent study of migration trends at older ages by Uren and Goldring ${ }^{7}$ found that around a third of people aged 50 and over in England and Wales had changed address during the period 1991-2001.

Litwak and Longino $(1987)^{8}$ identified three distinct types of migration at older ages: 'amenity' related or retirement migration undertaken to improve quality of life; disability or health-related migration, undertaken to move closer to kin; and finally moves into institutions towards the end of life. They highlight that the balance between these types of migration will vary across the life course, with migratory moves being intimately related to other life course events. Thus the characteristics of those undertaking life-style moves at retirement may be expected to vary significantly from those moving in later old age.

This article aims to explore the characteristics of older migrants (aged 50 and over) in the UK between 1991 and 2007 using data from the British Household Panel Survey (BHPS). It builds upon previous work by Grundy ${ }^{9}{ }^{10}$, Glaser and Grundy ${ }^{11}$ and Uren and Goldring ${ }^{7}$ both by extending the analysis to include a wider range of socio-economic characteristics and by investigating annual moves rather than moves in a ten year period. The availability of a range of data on annual transitions means that migratory moves may be more explicitly linked to the timing of other life course events such as divorce, widowhood or retirement. Older migrants are defined as those people who have changed residential address during the reference period. As such the article looks at all residential mobility rather than the more narrowly defined internal migration across administrative boundaries. The article is limited to those older people living in the community and does not explore moves into institutional care.

\section{Data Sources}

Data on internal migration, or residential mobility, in the UK are often limited as there is no legal obligation to register a change of address. Data from patient registers can be used to provide some estimates of the extent, or quantum, of internal migration ${ }^{12}$, but is restricted in the amount of detail available on the characteristics of the migrants themselves. Previous research on older migrants has tended to use data either from the census ${ }^{6}{ }^{13}$, or from the ONS Longitudinal Study ${ }^{711}$. Although the latter has the advantage of large sample sizes, being based on a one per cent sample of the census in England and Wales, data on the characteristics of the respondents is only available at ten yearly intervals and is limited to the information collected in the census, which excludes income and other indicators of financial well-being. In recent years national surveys such as the Labour Force Survey and General Household Survey, now the General LiFestyle Survey (GLF), which 
collect detailed information on a wider range of socio-economic characteristics have included questions on change of address in the last year. However, until recently, they have only provided cross-sectional data and do not allow investigation of migration and its relationship with other life course events. Moreover, in any given year, only a small number of older people sampled will have migrated, limiting the usefulness of these sources for examining migration in later life.

This article attempts to overcome these limitations by using pooled data from the British Household Panel Study (BHPS) over the period 1991 - 2007. The BHPS is a longitudinal, multi-purpose study carried out by the UK Longitudinal Studies Centre and offers a wide array of variables to explore the profile of older migrants. As the data is longitudinal, it is possible to investigate how life course events, such as experiencing a divorce or being widowed, are associated with a migratory move in the same period. It is important to note that migration here refers to any change of address. This differs from standard approaches; demographers often think of migration as only moves between statistical areas, with within-area movement being termed 'residential mobility'. In this article, the terms 'migration', 'residential mobility' and 'change of address' are used interchangeably.

In order to overcome the problem of migration being a relatively rare event at older ages, observations from all 17 waves of the BHPS are used to create a pooled dataset. Respondents in adjacent waves are matched using the cross-wave person identifier to create a series of subsets containing the characteristics of the respondents at two points in time (t1 and t2). For example, respondents in 1991 are matched with their responses in 1992 to create a subset for 1991-92, data from 1992 are matched with 1993, and so on, until 2006-07. The resulting 16 paired year subsets are then merged to create the final dataset. Respondents who only provide one interview at one of the two successive waves are necessarily excluded. For the purposes of this analysis, the sample is then restricted to respondents aged 50 and over at $\mathrm{t} 1$. This yielded a total sample size of 71,356 people aged 50 and over, of whom 2,397 (3.4 per cent) have migrated between $\mathrm{t} 1$ and $\mathrm{t} 2$. Of these 335 are serial migrants, as they have changed address both between $\mathrm{t} 0$ and $\mathrm{t} 1$, and then again between $\mathrm{t} 1$ and $\mathrm{t} 2$.

The BHPS is a panel survey which follows the same individuals over time, this means that the same individuals may appear in the pooled paired year dataset more than once. For example, an individual who was aged 75 in 1991, and who was interviewed in each of the first six waves of the panel, will appear in the dataset five times. This means that the results may be confounded by correlation within cases over time ${ }^{14}$. However, this disadvantage is offset by the greater statistical power and reliability of estimation afforded by the larger sample size.

\section{Identifying migrants}

The BHPS collects information on respondent's address one year ago. It is therefore possible to identify migrants in several ways. In wave 1, those older people who answered that they were not resident at their current address one year prior to the interview, may be thought of as having migrated between $\mathrm{t} 0$ and $\mathrm{t} 1$. Similarly in wave 2 , those who answered that they were not resident at their current address one year prior to the interview, may be thought of as having migrated between $\mathrm{t} 1$ and $\mathrm{t} 2$. Finally, those who answered that they were not resident at their current address one year prior to the interview in both wave 1 and 2 , may be thought of as experiencing serial migration.

As this article is primarily interested in understanding the characteristics that are associated with a move in order to be better able to forecast local population needs, older migrants are defined here 
as those who move between $\mathrm{t} 1$ and $\mathrm{t} 2$. This allows us to investigate which demographic and socioeconomic characteristics at $\mathrm{t} 1$ are associated with a move in the following 12 months (interviews between waves are usually 12 months apart). As the data are limited to people who are resident in households at the time of the BHPS survey, migration into institutions is not observed. The inclusion of the variable 'survey year' in the dataset allows investigation of period effects, such as changes in policy, economic climate and political context.

\section{Life course events}

Previous research has shown that migration behaviour is closely associated with other life course events $^{8}$. The rich longitudinal data available from the BHPS allows us to construct a series of variables that capture key life course transitions, such as getting married, divorced or widowed, becoming unemployed or retiring or experiencing deteriorating (or improving) physical and mental health.

A series of variables capturing these key life transitions are derived as follows:

- Newly partnered (not partnered at $\mathrm{t} 1$ and partnered (defined as married, cohabiting or in civil partnership) at t2)

- Newly divorced/separated (partnered at $\mathrm{t} 1$ and divorced/separated at $\mathrm{t} 2$ )

- Newly widowed (partnered/separated at $\mathrm{t} 1$ and widowed t2)

- Newly unemployed (employed at $\mathrm{t} 1$ and unemployed at $\mathrm{t2}$ )

- Newly self-employed (employed or unemployed at $\mathrm{t} 1$ and self-employed at $\mathrm{t} 2$ )

- Newly retired (economically active at t1and retired at $\mathrm{t} 2$ )

It is important to note that we do not have information on the exact timing of these life course events and how they relate to the timing of migration during the year. If migrations are spread evenly across the year, some will have occurred only weeks or even days before the interview at t2. Similarly, the changes in marital status or economic activity may have occurred at any stage between the two interviews. The variables do not allow us to investigate causation, but simply to capture life course events that occur in the same period as a change in address.

\section{Health}

The BHPS contains a number of measures of health including general health status over the past year (measured using a five response Likert scale of excellent, good, fair, poor or very poor) and whether a person suffers from a long-term illness that limits their activity.

Given that data are available at two points in time, it is possible to create a variable that captures changes in self-reported health status across time. Here an improvement in health is defined as experiencing an upward movement of more than one category in self-reported health status between $\mathrm{t} 1$ and $\mathrm{t} 2$; that is, a move from fair to excellent, or a move from poor to good or excellent, or a move from very poor to fair, good or excellent (shaded pale blue in Figure 1). Similarly, a deterioration in health is defined as experiencing a downward movement of more than one category between $\mathrm{t} 1$ and $\mathrm{t} 2$; that is from excellent to fair, poor or very poor, or from good to poor or very poor, or from fair to very poor (shaded dark blue). Health is defined as staying the same if the respondent reports the same health status, plus or minus one category, at both points in time (shaded grey). 


\section{Figure 1 Five response Likert scale for measuring change in health status over time with three outcomes}

\begin{tabular}{|c|c|c|c|c|c|c|}
\hline & & \multicolumn{5}{|c|}{ General health status in $\mathrm{t} 2$} \\
\hline & & Excellent & Good & Fair & Poor & Very poor \\
\hline \multirow{5}{*}{$\begin{array}{l}\text { General health } \\
\text { status in } \mathrm{t} 1\end{array}$} & Excellent & & & & & \\
\hline & Good & & & & & \\
\hline & Fair & & & & & \\
\hline & Poor & & & & & \\
\hline & Very poor & & & & & \\
\hline
\end{tabular}

\section{Results}

Table 1 shows the percentage of older people who changed address between two successful waves of the BHPS over the period 1991-2007. Overall 3.4 per cent of people aged 50 and over migrated between two waves and there is no overall difference by gender. However, there are clear gender differences by age, with the migration level being significantly higher for women than for men at ages 80-84 and 85-89 (see Figure 2). This may in part reflect sex differentials in mortality and the higher likelihood of women being widowed and then moving at these ages.

\section{Table 1 People aged $\mathbf{5 0}$ and over who migrated between waves, by age at start of the period, UK}

\begin{tabular}{lrrrrrr}
\hline \multirow{2}{*}{ Age group } & \multicolumn{2}{c}{ Males } & \multicolumn{2}{c}{ Females } & \multicolumn{2}{c}{ All } \\
& $\begin{array}{l}\text { Per cent } \\
\text { migrating }\end{array}$ & $\begin{array}{c}\text { Number } \\
\text { in sample }\end{array}$ & $\begin{array}{c}\text { Per cent } \\
\text { migrating }\end{array}$ & $\begin{array}{c}\text { Number } \\
\text { in sample }\end{array}$ & $\begin{array}{c}\text { Per cent } \\
\text { migrating }\end{array}$ & $\begin{array}{c}\text { Number } \\
\text { in sample }\end{array}$ \\
\hline $50-54$ & 4.4 & 6,618 & 3.8 & 7,809 & 4.1 & 14,427 \\
$55-59$ & 3.7 & 5,927 & 3.7 & 6,978 & 3.7 & 12,905 \\
$60-64$ & 3.5 & 5,030 & 3.1 & 5,937 & 3.3 & 10,967 \\
$65-69$ & 3.0 & 4,595 & 2.8 & 5,413 & 2.9 & 10,008 \\
$70-74$ & 2.3 & 4,127 & 2.6 & 5,187 & 2.4 & 9,314 \\
$75-79$ & 2.9 & 2,862 & 2.7 & 4,137 & 2.8 & 6,999 \\
$80-84$ & 2.1 & 1,662 & 4.1 & 2,725 & 3.3 & 4,387 \\
$85-89$ & 3.4 & 644 & 5.5 & 1,190 & 4.8 & 1,834 \\
$90+$ & 5.8 & 154 & 5.5 & 361 & 5.6 & 515 \\
All ages & & & & & & \\
\hline
\end{tabular}

Source: authors' own analysis of pooled paired year BHPS data 1991-2007.

The relationship between migration and age is U-shaped. For both men and women the likelihood of migrating decreases with age until the late 70 s or early $80 \mathrm{~s}$, at which point the likelihood starts to increase. This is a similar finding to that of Conway and Rork in their study of old age migration in the USA ${ }^{15}$. They also argued that that those moving at younger ages tend to do so on the grounds of amenity, that is, moving to improve life style, whereas those who move at oldest-old ages move because they may need assistance in terms of informal or formal care provision. As the BHPS data excludes moves into institutions, the percentage migrating at ages 80 and over is likely to be considerably higher than the percentages shown in Figure 2. 


\section{Figure 2 People aged $\mathbf{5 0}$ and over migrating between waves by sex and age group, percentage, UK}

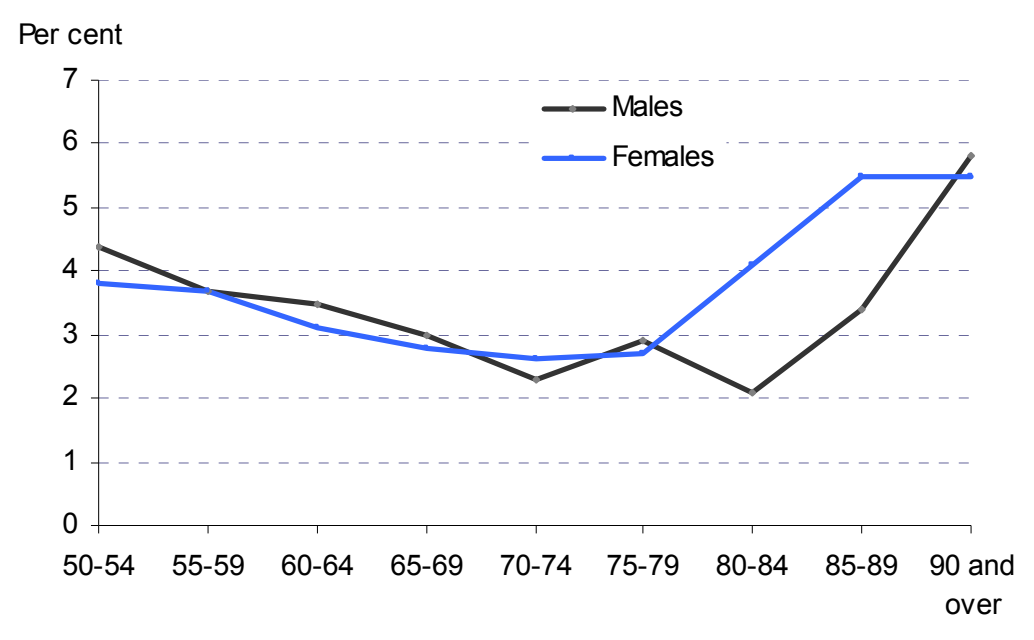

Age at start

Source: authors' own analysis of pooled paired year BHPS data 1991-2007.

\section{Partnership status}

Previous analyses have shown that changes in partnership status may influence an individual's decision to migrate in later life ${ }^{7811}$. Figure $\mathbf{3 a}$ and $\mathbf{3 b}$ highlight the differences in the likelihood of experiencing a migratory move according to partnership status at the start of the period by age. Living as a couple includes those who are legally married, or in a civil partnership, as well as cohabiting couples. At ages under 70 the proportion migrating in the coming year, that is between $\mathrm{t} 1$ and $\mathrm{t} 2$, is much higher among those men, who report being divorced at the start of the period, compared to all other groups, while at older ages, it is those men who are widowed, who are most likely to experience a move. This pattern is also evident among women, although the differentials by partnership status are less marked. Table 2 sheds further light on the relationship between partnership status and migration by separating those older people who experience a change in their relationship status between successive interviews from those who do not.

\section{Table 2 People aged 50 and over who migrated between waves, by partnership status at the end of the period, UK}

\begin{tabular}{|c|c|c|c|c|c|c|}
\hline & \multicolumn{2}{|c|}{ Males } & \multicolumn{2}{|c|}{ Females } & \multicolumn{2}{|c|}{ All } \\
\hline & $\begin{array}{l}\text { Per cent } \\
\text { migrating }\end{array}$ & $\begin{array}{c}\text { Number } \\
\text { in sample }\end{array}$ & $\begin{array}{l}\text { Per cent } \\
\text { migrating }\end{array}$ & $\begin{array}{c}\text { Number } \\
\text { in sample }\end{array}$ & $\begin{array}{l}\text { Per cent } \\
\text { migrating }\end{array}$ & $\begin{array}{c}\text { Number } \\
\text { in sample }\end{array}$ \\
\hline Newly partnered & 25.0 & 164 & 17.5 & 177 & 21.1 & 341 \\
\hline Continuing couple & 2.9 & 24,323 & 2.8 & 22,850 & 2.9 & 47,173 \\
\hline Newly widowed & 5.6 & 324 & 5.2 & 688 & 5.3 & 1,012 \\
\hline Continuing widowed & 3.0 & 2,777 & 3.7 & 10,176 & 3.6 & 12,953 \\
\hline Newly divorced/separated & 21.6 & 171 & 11.3 & 301 & 15.0 & 472 \\
\hline Continuing divorced/separated & 5.6 & 1,781 & 4.8 & 3,272 & 5.1 & 5,053 \\
\hline Never married & 3.4 & 2,068 & 2.9 & 2,263 & 3.1 & 4,331 \\
\hline All & 3.4 & 31,608 & 3.4 & 39,727 & 3.4 & 71,335 \\
\hline
\end{tabular}

Source: authors' own analysis of pooled paired year BHPS data 1991-2007. 


\section{Table $3 a \quad$ Men migrating between waves by age and marital status}

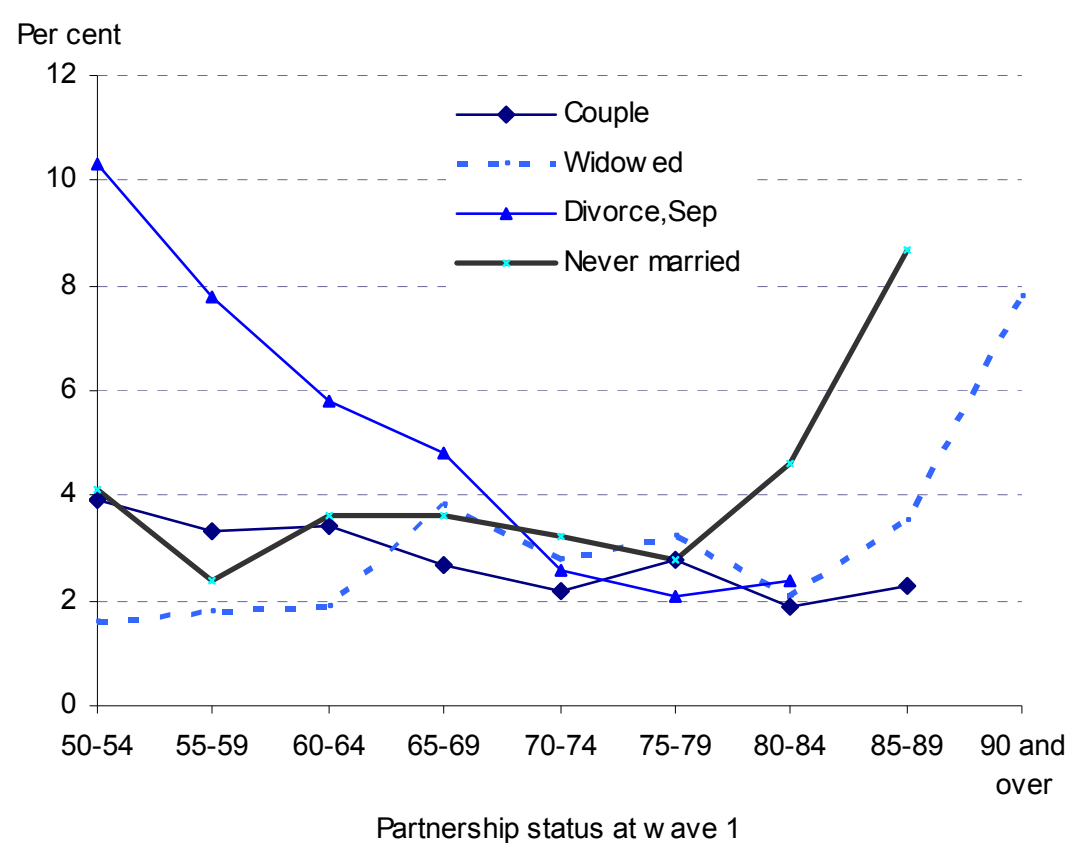

Note: Data points where $\mathrm{N}<20$ are excluded

Source: authors' own analysis of pooled paired year BHPS data 1991-2007.

\section{Table $3 b \quad$ Women migrating between waves by age and marital status}

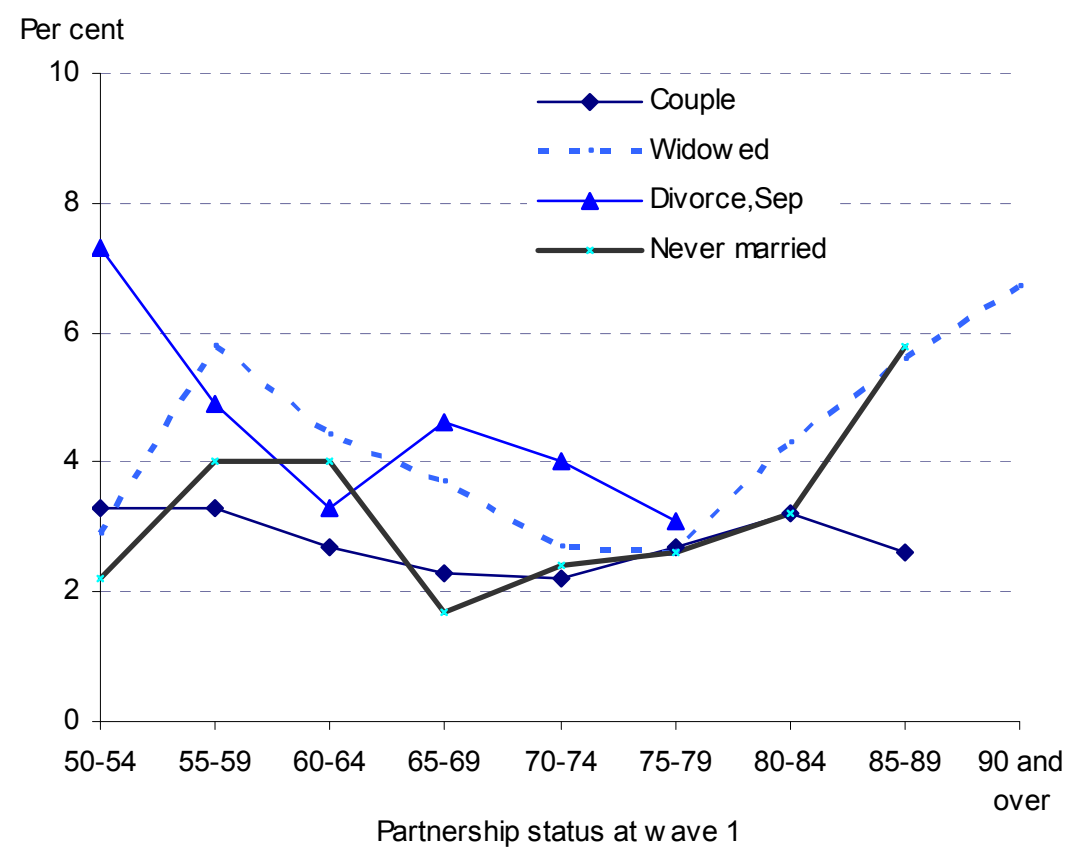

Note: Data points where $\mathrm{N}<20$ are excluded

Source: authors' own analysis of pooled paired year BHPS data 1991-2007.

Migration is highest among those older men and women who have formed a new partnership, with 25 percent of men and 17.5 percent of women who have married, started cohabiting, or entered 
into a civil partnership between $\mathrm{t} 1$ and $\mathrm{t} 2$, also changed address during the year. Experiencing a breakdown in relationship is also strongly associated with a move, with 21.6 percent of men and 11.3 percent of women, who divorced or separated from a partnership between waves, also changed their place of residence ${ }^{16}$. There is also clear evidence of a relationship between recent widowhood and migration, with those who were newly widowed being almost twice as likely to move as those who were widowed previously. This is similar to results obtained in the USA using data from the Panel Study of Income Dynamics ${ }^{17}$.

Table 2 also provides some evidence that the impact of relationship breakdown on the likelihood of migrating persists beyond the first year, with those older men and women who are 'continuing divorcees or separatees' being nearly as likely to migrate as those who are newly widowed. Interestingly, six per cent of those who are newly partnered and two per cent of those who are newly divorced/separated are serial movers (that is, they changed address both between $\mathrm{t} 1$ and $\mathrm{t} 2$ and also in the previous year between t0 and t 1 ). This compares with just 0.5 percent of all people aged 50 and over, which further reinforces the notion that changes in relationship are an important trigger for residential mobility. As divorce and remarriage become more common in later life, it is perhaps time for the classic Litwak and Longino ${ }^{8}$ typology of old age migration to be extended by the inclusion of a fourth category, that is 'relationship driven migration'.

\section{Socio-economic characteristics}

The relationship between socio-economic circumstances and migration in later life is not clear cut. Studies in North America by Meyer and Speare ${ }^{18}$ and Moore and Rosenberg ${ }^{19}$ found that individuals with fewer financial constraints were more likely to migrate than those older people on lower incomes. In contrast, Silverstein ${ }^{20}$ found that those with lower incomes were more likely to reduce the temporal distance between themselves and their children. These types of moves have been branded by Conway and Rork ${ }^{15}$ as 'assistance moves', where individuals move towards family or other support systems. Clark and White ${ }^{21}$, focusing on the relationship between income and mobility among older people living in the rented sector, found that older renters were more likely to migrate if they had low or high income, as opposed to middle income. Similarly Walters ${ }^{22}$ and Wiseman ${ }^{23}$ have found that older migrants were more likely to have, either above average incomes (amenity migrants), or lower incomes (assistance migrants).

Analysis of the BHPS data found no significant difference in the level of migration for those aged over 50 according to the relative income position of the older person (annual income was recoded into quintiles within years to avoid problems of inflation over time). The only exception to this was for those aged 60-69, where people who were ranked in the bottom quintile, that is the poorest 20 percent, were less likely to move (2.4 per cent) than the age group as a whole ( 3.1 per cent). This suggests that financial position may play a role in facilitating moves around the time of retirement, but does not play such an important role in the UK at other stages. However, that is not to say that economic factors are unimportant.

Table 3 shows migration percentages for men and women aged 50 and over by their economic activity status at $\mathrm{t} 1$. Those men and women, who are unemployed at the start of the period, are significantly more likely to migrate during the following 12 months than those who are employed. So too are those who are self-employed or long term sick or disabled, while those who are retired are less likely to migrate. 


\section{Table 3 People aged 50 and over who migrated between waves, by economic activity status at the start of the period, UK}

\begin{tabular}{lrrrrr}
\hline Economic activity status & \multicolumn{2}{c}{ Males } & \multicolumn{2}{c}{ Females } \\
& $\begin{array}{r}\text { Per cent } \\
\text { migrating }\end{array}$ & $\begin{array}{r}\text { Number } \\
\text { in sample }\end{array}$ & $\begin{array}{r}\text { Per cent } \\
\text { migrating }\end{array}$ & $\begin{array}{r}\text { Number } \\
\text { in sample }\end{array}$ \\
\hline Employed & & & & & \\
Self-employed & 3.4 & 9,513 & 3.2 & 10,198 \\
Unemployed & 4.9 & 3,386 & 5.0 & 1,062 \\
Retired & 2.9 & 15,357 & 6.6 & 471 \\
Long term sick/disabled & 4.5 & 2,157 & 3.2 & 21,097 \\
Other (incl. keeping house, FT student) & 3.8 & 370 & 4.9 & 1,920 \\
All & & & 3.0 & 4,989 \\
\hline
\end{tabular}

Source: authors' own analysis of pooled paired year BHPS data 1991-2007.

Again it is interesting to investigate whether changes in economic activity status over the year are associated with a move during that year. Table 4 therefore distinguishes between those who continue in the same economic activity status and those who have newly acquired that status. In all cases, with the exception of women who are unemployed or long term sick, migration among 'new entrants' is higher than among 'stayers'. This again demonstrates the inter-dependency of different life course events, with residential moves often being associated with changes in employment status.

\section{Table $4 \quad$ People aged $\mathbf{5 0}$ and over who migrated between waves by economic activity status at the end of the period, UK}

\begin{tabular}{lrrrr}
\hline Economic activity status & \multicolumn{2}{c}{ Males } & \multicolumn{2}{c}{ Females } \\
& $\begin{array}{r}\text { Per cent } \\
\text { migrating }\end{array}$ & $\begin{array}{r}\text { Number } \\
\text { in sample }\end{array}$ & $\begin{array}{r}\text { Per cent } \\
\text { migrating }\end{array}$ & $\begin{array}{r}\text { Number } \\
\text { in sample }\end{array}$ \\
& & & & \\
Newly employed & 4.0 & 683 & 4.1 & 652 \\
Continuing employed & 3.1 & 8,252 & 2.8 & 8,857 \\
Newly self employed & 6.8 & 395 & 4.6 & 239 \\
Continuing self employed & 3.7 & 2,847 & 3.1 & 775 \\
Newly unemployed & 6.6 & 364 & 6.7 & 283 \\
Continuing unemployed & 3.8 & 365 & 9.9 & 121 \\
Newly retired & 5.3 & 1,543 & 5.0 & 2,759 \\
Continuing retired & 2.8 & 14,736 & 3.2 & 19,512 \\
Newly long term sick & 5.8 & 591 & 4.6 & 627 \\
Continuing long term sick & 4.3 & 1,598 & 4.7 & 1348 \\
Other & 6.3 & 254 & 3.1 & 4,564 \\
All & & & & 3.4 \\
\hline
\end{tabular}

Source: authors' own analysis of pooled paired year BHPS data 1991-2007.

Housing tenure is often used as an indicator of socio-economic status in the UK. Previous studies have found tenure to be strongly related to the propensity to migrate in later life ${ }^{7910}$. Table 5 illustrates that among people aged 50 and over, migration is highest for those living in privately rented accommodation, and especially for the minority renting in the furnished private sector (19 per cent). Figure 4 confirms for all age groups that those living in privately rented accommodation are the most likely to move, although the differential according to tenure decreases with age. 


\section{Figure 4 People aged $\mathbf{5 0}$ and over migrating by household tenure and age group, percentage, UK}

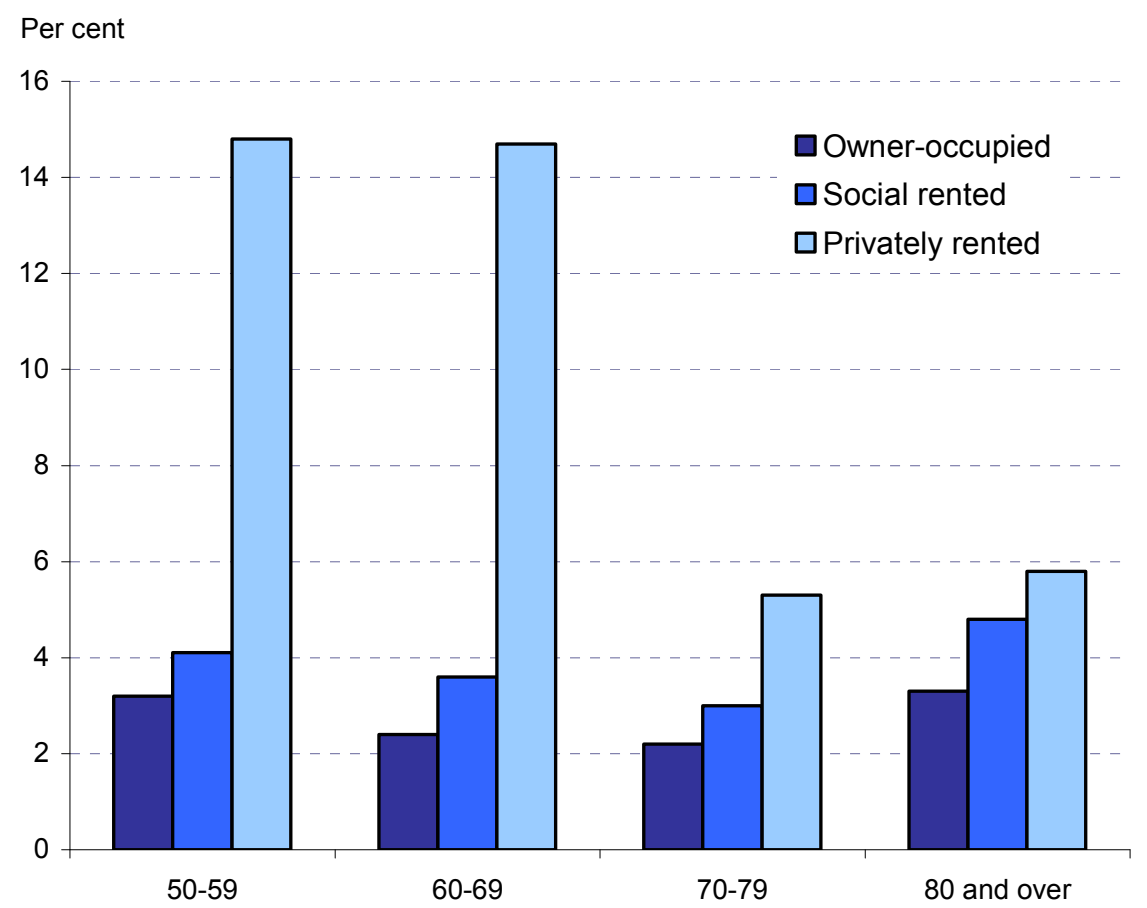

Source: authors' own analysis of pooled paired year BHPS data 1991-2007.

\section{Table 5 People aged $\mathbf{5 0}$ and over who migrated between waves by housing tenure at the start of the period, percentages, UK}

\begin{tabular}{lrr}
\hline Tenure type & \multicolumn{2}{c}{ Males } \\
& $\begin{array}{r}\text { Per cent } \\
\text { migrating }\end{array}$ & $\begin{array}{r}\text { Number in } \\
\text { analysis }\end{array}$ \\
\hline Owners outright & 2.5 & 36,323 \\
Owns with a mortgage & 3.3 & 16,801 \\
Local authority rented & 3.3 & 11,483 \\
Housing association rented & 5.0 & 2,799 \\
Rented from Employer & 11.1 & 488 \\
Other privately rented unfurnished & 9.7 & 2,248 \\
Other privately rented furnished & 19.2 & 646 \\
All & 3.4 & $\mathbf{3 1 , 6 1 9}$ \\
\hline
\end{tabular}

Source: authors' own analysis of pooled paired year BHPS data 1991-2007.

\section{Health}

In a similar fashion to the relationship between migration and wealth discussed above, the relationship between health and migration has also been postulated as being U-shaped ${ }^{24}$. It is argued that good health may help facilitate amenity driven moves in early old age, while poor health may act as a trigger for an assistance move at older ages. 
Figure $\mathbf{5 a}$ and $\mathbf{5 b}$ confirm the positive association between migration and poor health at older ages, with much higher migration for men and women with a limiting long term illness at ages 80 and over. However, migration levels for those with a limiting long term illness are also higher than for those who do not suffer from a long term illness at younger ages. This suggests that it is too simplistic to assume that all migration at younger old ages (50-69 years) is amenity driven, but rather, that migration for these age groups may be a mixture of both amenity and health related migration. This picture is further supported by Table 6, which shows migration percentages by self reported health status by age group. There is little evidence of a $U$-shaped relationship, but rather, that the percentage migrating tends to rise for all age groups as health worsens.

\section{Table 6 Percentage of men and women migrating by self reported health status at the start of the period and age group, UK}

\begin{tabular}{lcccc}
\hline $\begin{array}{l}\text { Health status over the } \\
\text { last } \mathbf{1 2} \text { months at } \mathbf{1 1}\end{array}$ & $\begin{array}{l}\text { Aged } \\
\mathbf{5 0 - 5 9}\end{array}$ & $\begin{array}{c}\text { Aged } \\
\mathbf{6 0 - 6 9}\end{array}$ & $\begin{array}{c}\text { Aged } \\
\mathbf{7 0 - 7 9}\end{array}$ & $\begin{array}{c}\text { Aged } \\
\mathbf{8 0 - 8 9}\end{array}$ \\
\hline Men & & & & \\
$\quad$ Excellent & 4.5 & 3.3 & 2.0 & 2.2 \\
$\quad$ Good & 3.7 & 2.7 & 2.1 & 2.1 \\
$\quad$ Fair & 3.5 & 3.6 & 2.6 & 3.9 \\
$\quad$ Poor & 4.5 & 3.8 & 3.9 & 3.6 \\
$\quad$ Very poor & 9.5 & 6.3 & 5.0 & - \\
$\quad$ & & & & \\
Women & & & & \\
$\quad$ Excellent & 4.0 & 2.7 & 2.1 & 4.0 \\
$\quad$ Good & 3.1 & 2.8 & 2.2 & 4.2 \\
$\quad$ Fair & 4.3 & 2.9 & 3.2 & 4.6 \\
$\quad$ Poor & 5.0 & 3.7 & 3.7 & 6.3 \\
$\quad$ Very poor & 3.4 & 3.5 & 2.8 & 7.3 \\
\hline
\end{tabular}

Source: authors' own analysis of pooled paired year BHPS data 1991-2007.

As with partnership status and economic activity, the BHPS data allows us to look at how changes in health are related to migration. As discussed above, an improvement in health was defined as experiencing an upward movement of more than one category in self reported health status between $\mathrm{t} 1$ and $\mathrm{t} 2$, while a deterioration in health was defined as experiencing a downward movement of more than one category between $\mathrm{t} 1$ and $\mathrm{t} 2$. Health was defined as staying the same if the respondent reported the same health or plus or minus one category.

In contrast to previous studies ${ }^{24}$, Figure 6 shows that at ages 50-69 men and women whose health has deteriorated between waves have similar migration levels to those whose health has improved, while at ages 70-79 migration is highest among those whose health has improved. The direction of causation is not clear. On the one hand changing one's place of residence may result in improved subjective well-being and therefore self-perceived health. Alternatively, improved health may have facilitated the migratory move. Whatever is the case, this highlights that the relationship between health status and migration is more complex than at first sight. 


\section{Figure $5 \mathrm{a}$ Men aged 50 and over migrating by having a limiting long term illness and age at $\mathrm{t} 1$}

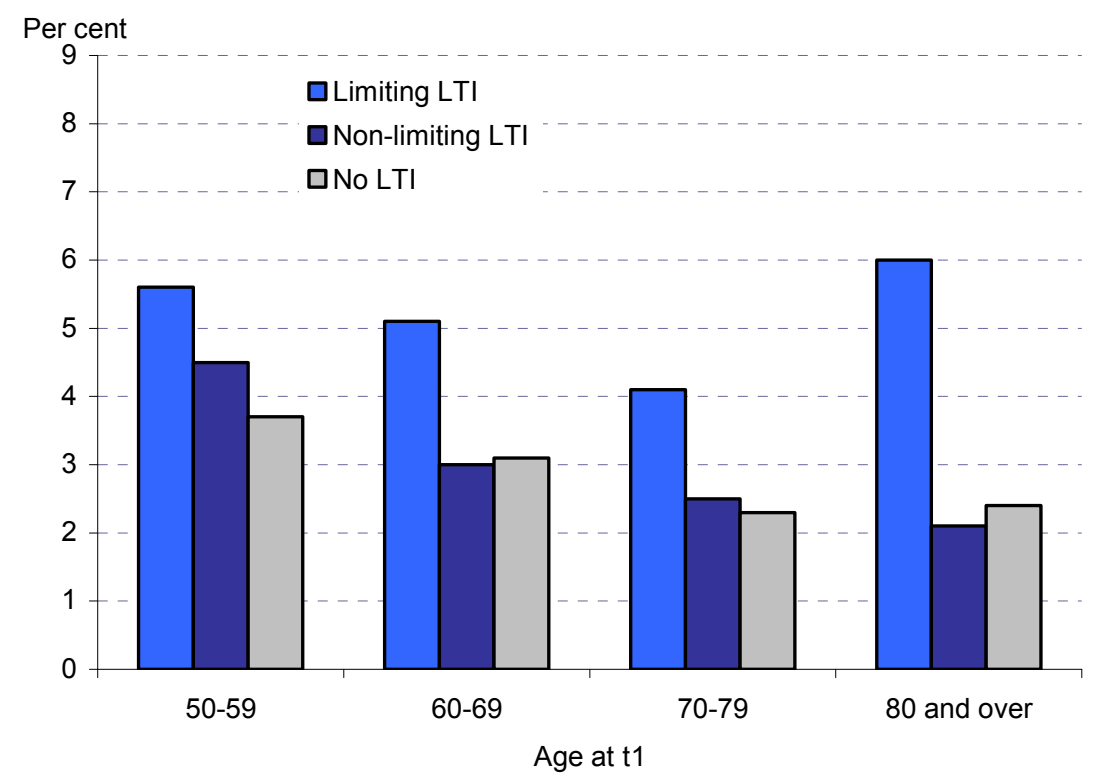

Source: authors' own analysis of pooled paired year BHPS data 1991-2007.

Figure $5 b$ Women aged $\mathbf{5 0}$ and over migrating by having a limiting long term illness and age at $\mathrm{t} 1$

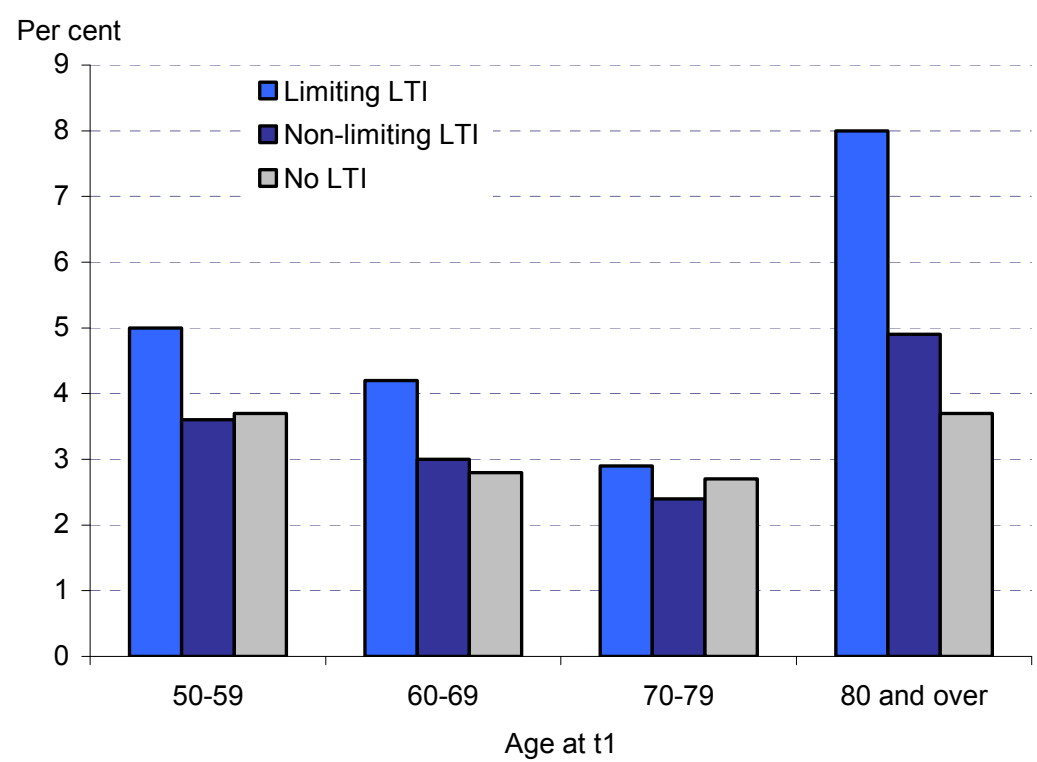

Source: authors' own analysis of pooled paired year BHPS data 1991-2007. 


\section{Figure 6 People aged 50 and over migrating by change in health status (t1- t2) and age group at $\mathrm{t} 1$}

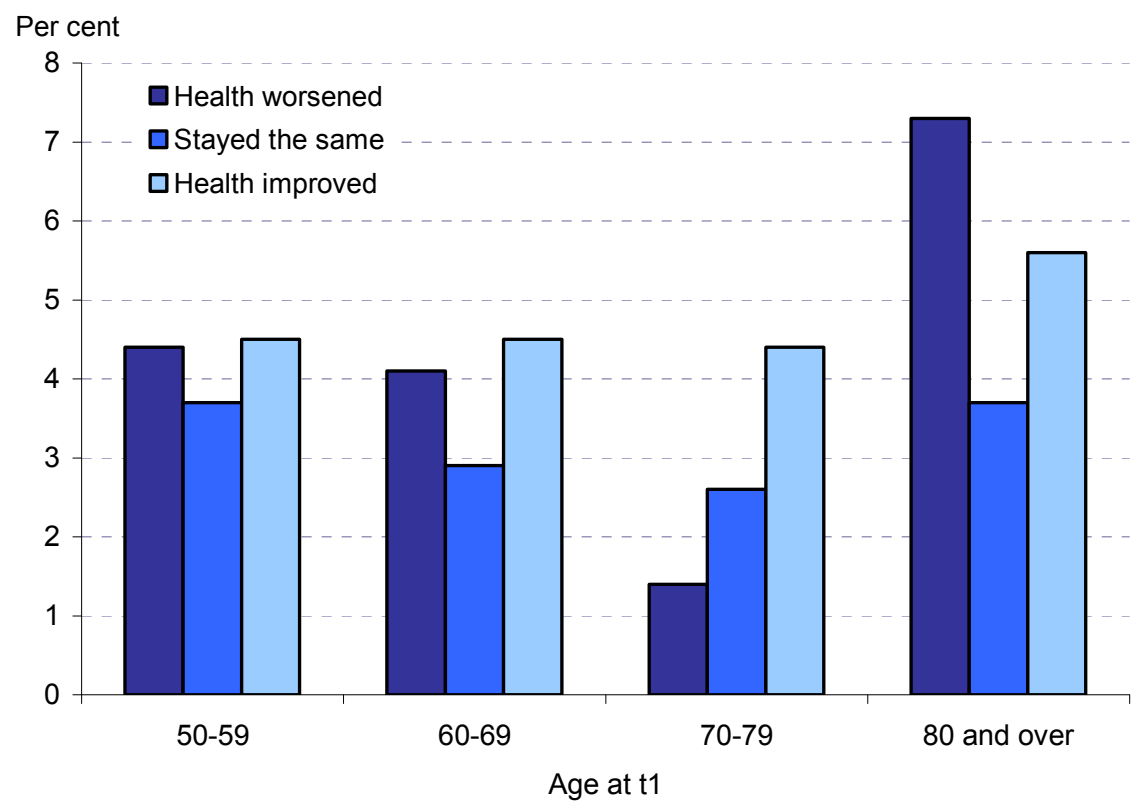

Source: authors' own analysis of pooled paired year BHPS data 1991-2007.

\section{Migration and life course transitions}

So far, we have examined the relationship between migration and older individuals' socioeconomic characteristics and life course transitions separately. Table 7 explores the extent to which these factors remain significant after controlling for other things. Living in rented accommodation remains significantly associated with increased mobility in later life, indicating that those older people in the private rented sector are more able to change their housing options than owner occupiers.

Changes in partnership status also remain highly significant, with those older people who enter into a new partnership being over six times more likely to move during the year compared with those who are never married. Conversely, those who divorce or separate are nearly five times as likely to move. Previous research has highlighted widowhood as a key risk factor and those who are newly widowed are twice as likely to move as the never married. However, there is no significant elevated risk of migrating among the continuing widowed. The heightened likelihood of moving among older people who are divorced, does however, persist.

Retirement is also an important risk factor for moving, but so too is exit from the labour market through unemployment and/or becoming self employed. Fielding's 'escalator region' work in the early 1990s using ONS Longitudinal Study 1971-1981 highlighted the distinctive migration of older people into self-employment (or the 'petite bourgeoisie' in his vocabulary), especially in moves from South East England to adjacent regions ${ }^{25}$, but these factors have received little attention in the more recent literature. 


\section{Table 7 Odds ratios of migrating between $\mathbf{t} 1$ and $\mathbf{t} 2$, persons aged $\mathbf{5 0}$ and over, 1991-2007, UK}

\begin{tabular}{|c|c|c|}
\hline & Odds ratio & $\begin{array}{c}95 \% \text { Confidence } \\
\text { interval }\end{array}$ \\
\hline \multicolumn{3}{|l|}{ Age at $\mathrm{t} 1{ }^{* * *}$} \\
\hline $50-5 \quad 4$ & 1.00 & \\
\hline $55-59$ & $0.87 *$ & $0.76-0.99$ \\
\hline $60-6 \quad 4$ & $0.69 * * *$ & $0.59-0.81$ \\
\hline $65-6 \quad 9$ & $0.58^{* \star *}$ & $0.48-0.71$ \\
\hline $70-7 \quad 4$ & $0.46^{\star * *}$ & $0.37-0.57$ \\
\hline $75-7 \quad 9$ & $0.50^{* * *}$ & $0.40-0.62$ \\
\hline $80-8 \quad 4$ & $0.56^{\star * *}$ & $0.44-0.71$ \\
\hline 85-89 & $0.73 *$ & $0.54-0.97$ \\
\hline $90+$ & 0.93 & $0.60-1.46$ \\
\hline \multicolumn{3}{|c|}{ General health status over last 12 months at $\mathrm{t} 1^{*}$} \\
\hline Exce llent & 1.00 & \\
\hline Good & 0.89 & $0.78-1.01$ \\
\hline $\mathrm{F} \quad$ air & 1.00 & $0.87-1.14$ \\
\hline Poor & 1.07 & $0.90-1.28$ \\
\hline Ver y poor & 1.16 & $0.89-1.50$ \\
\hline \multicolumn{3}{|l|}{ LLTI at $\mathrm{t} 1^{* * *}$} \\
\hline No limiting long term illness & 1.00 & \\
\hline Limitin $\quad \mathrm{g} \mathrm{LTI}$ & $1.41^{* * *}$ & $1.23-1.62$ \\
\hline Non-I imiting LTI & 1.06 & $0.96-1.18$ \\
\hline \multicolumn{3}{|l|}{ Partnership status at $t 2^{\star \star *}$} \\
\hline Never married & 1.00 & \\
\hline $\mathrm{Ne} \quad$ wly partnered & $7.64^{* * *}$ & $5.45-10.69$ \\
\hline Conti nuing couple & 1.01 & $0.83-1.22$ \\
\hline $\mathrm{Ne} \quad$ wly widowed & $1.89^{* * *}$ & $1.33-2.68$ \\
\hline Continuing widowed & $1.28 *$ & $1.03-1.59$ \\
\hline Newly divorced, separated & $5.41^{* * *}$ & $3.90-7.52$ \\
\hline Continuing divorced, separated & $1.52 * *$ & $1.21-1.91$ \\
\hline \multicolumn{3}{|l|}{ Economic status at $\mathbf{t}{ }^{* * *}$} \\
\hline Other & 1.00 & \\
\hline $\mathrm{Ne} \quad$ wly employed & 1.24 & $0.88-1.73$ \\
\hline Conti nuing employed & 0.84 & $0.69-1.03$ \\
\hline Newly self employed & 1.64 * & $1.10-2.46$ \\
\hline Continuing self employed & 1.00 & $0.77-1.30$ \\
\hline Newly unemployed & $1.70 * *$ & $1.17-2.47$ \\
\hline Conti nuing unemployed & 1.24 & $0.79-1.94$ \\
\hline $\mathrm{Ne} \quad$ wly retired & $1.73^{* * *}$ & $1.38-2.17$ \\
\hline Conti nuing retired & 1.20 & $0.98-1.46$ \\
\hline Newly long term sick & 1.31 & $0.95-1.82$ \\
\hline Continuing long term sick & 0.93 & $0.71-1.22$ \\
\hline \multicolumn{3}{|l|}{ Tenure at $t 1^{* * *}$} \\
\hline O wned & 1.00 & \\
\hline Social rented & 1.19 ** & $1.06-1.33$ \\
\hline Privatel y rented & $4.05^{\star * *}$ & $3.55-4.62$ \\
\hline
\end{tabular}

Variables entered in forward conditional step wise model in the following order: tenure, partnership status, economic status, age, limiting long term illness, general health status.

Change in health status, sex and year were not significant

*** $p<0.001 \quad$ ** $p<0.01 \quad$ * $p<0.05$

Source: authors' own analysis of pooled paired year BHPS data 1991-2007. 
The U-shaped relationship with age also remains, with the likelihood of moving being highest at ages 50-54 once health and widowhood (two factors strongly associated with moving at older ages) are taken into account. Interestingly, the two health variables were the last of the variables to be selected into the model, despite the emphasis in the literature on health as a determinant of migration in later life. In part this reflects the fact that this study is restricted to moves within the community and thus excludes moves into residential care. The BHPS does contain information on those who are lost to follow up through moves into institutions where the household remains in the survey, and future work will attempt to explore this further.

\section{Conclusion}

Typologies of migration patterns in later life have largely concentrated on classifying moves into two broad groups, those associated with improved lifestyle around the time of retirement and moves later in life associated with failing health. Our research has confirmed that both are important factors associated with moving at ages post 50 . However, focussing on these two types of moves risks missing a key part of the picture. In particular, migration in later life - as is also the case at younger ages - is strongly associated with the formation and dissolution of partnerships. Moreover, the impact of partnership dissolution has a persisting effect with older people who are divorced or separated being more likely to move than the never married even after the first year of partnership breakdown. As re-partnering becomes increasingly common in older ages, it will be important that policy makers and planners take this into account.

\section{Key findings}

- Around 3.5 per cent of all people aged 50 and over living in private households move addresses each year and this figure has been relatively constant across time.

- The likelihood of migrating decreases with age until the late 70 s/early 80 s when the likelihood rises.

- Those older people living in rented housing are more likely to move than those living in owner occupied housing, with those living in the private rented sector experiencing higher migration than those living in the social rented sector.

- The likelihood of migrating in later life is strongly linked to other life course events:

- Forming a new partnership or experiencing a breakdown in an existing partnership, either through divorce or widowhood, can be an important trigger for a move.

- Exit from the labour market through retirement or unemployment is also associated with migration.

- Existing typologies of migration in later life may need to be adapted to reflect changes in social norms as re-partnering at older ages becomes more common.

- Poor health may also trigger a move. However, the relationship between migration and health is not straightforward with higher migration at ages 70-79 among those whose health has improved during the year in which the move has taken place. 


\section{Acknowledgements}

Maria Evandrou and Jane Falkingham are co-Directors of the ESRC Centre for Population Change (CPC) funded by ESRC Grant number RES-625-28-001. Marcus Green is a PhD student within the Centre. The Centre for Population Change (CPC) is a joint initiative between the University of Southampton and a consortium of Scottish Universities in partnership with ONS and GROS. Maria Evandrou is the Director of the Centre for research on ageing at the University of Southampton.

The authors are grateful for the constructive comments from the anonymous reviewers. The findings, interpretations, and conclusions expressed in this article are entirely those of the authors and should not be attributed in any manner to ONS or GROS. Data from the British Household Panel Survey (BHPS) were supplied by the UK Data Archive. Neither the original collectors of the data nor the archive bear any responsibility for the analysis or interpretations presented here.

\section{References}

1 Office for National Statistics (2010) 2009 Mid-year population estimates. Available at: www.statistics.gov.uk/statbase/Product.asp?vlnk=15106

2 Williams, AM, King, R and Warnes, AM (1997) 'A Place in the Sun; International Retirement Migration from Northern to Southern Europe'. European Urban and Regional Studies, Vol 4 (2) 115-134.

3 King, R, Warnes, AM and Williams, AM (1998) 'International Retirement Migration in Europe'. International Journal of Population Geography 4: 91-111.

4 Warnes, AM and Patterson, G (1998) 'British Retirees in Malta: Components of the CrossNational Relationship'. International Journal of Population Geography 4: 113-133.

5 King, R, Warnes, AM and Williams, AM (2000) Sunset Lives: British Retirement Migration to the Mediterranean. Oxford; Berg.

6 Green, M, Evandrou, M and Falkingham, J (2009) 'Older International Migrants: who migrates to England and Wales in later life?' Population Trends 137: 33-40.

7 Uren, Z and Goldring, S (2007) 'Migration Trends at Older Ages in England and Wales'. Population Trends 130: 31-40. Available at:

www.statistics.gov.uk/statbase/Product.asp?vink=6303

8 Litwak, E and Longino, C (1987) 'Migration Patterns Among the Elderly'. The Gerontologist, 7 (3) $266-272$.

9 Grundy, E (1987) 'Retirement Migration and Its Consequences in England and Wales'. Ageing and Society, 7: 57-82.

10 Grundy, E (1993) 'Moves into Supported Private Households among Elderly People in England and Wales'. Environment and Planning A, 25: 1467-1479.

11 Glaser, K and Grundy, E (1998) 'Migration and Household Change in the Population Aged 65 and over, 1971-1991'. International Journal of population Geography 4: 323-339. 
12 Scott, A and Kilbey, T (1999) 'Can patient registers give an improved measure of internal migration in England and Wales? Population Trends 96: 44-45.

13 Warnes, AM (1996) 'Migrations among older people'. Reviews in Clinical Gerontology 6:101114.

14 Menard, S (2002) Longitudinal Research. Sage University Paper Series on Quantitative Applications in the Social Science no. 76. Thousand Oaks, CA, Sage.

15 Conway, K and Rork, J (2008) Elderly and Non-Elderly Interstate Migrants - The Changing Roles of Socioeconomic, Disability and Veteran Status. National Institutes of Health.

16 It is somewhat surprising that these figures are not higher, suggesting that a high proportion of older people who experience a partnership breakdown are still co-resident. There are several possible explanations. Firstly, one partner may have already migrated before the reference year when the divorce/separation was reported. Secondly, the BHPS may be biased towards those who remained in the family home, thus under-reporting on those who have moved as a result of breakdown. Further work is needed in order to identify both partners, in order to assess how many older men and women could not be traced following a breakdown.

17 Chevan, A (2005) 'Holding On and Letting Go: Residential Mobility during Widowhood'. Research on Aging, 17 (3) 278-302.

18 Meyer, J and Speare, A (1985) 'Distinctively Elderly Mobility: Types and Determinants'. Economic Geography, 61: 79-88.

19 Moore, E and Rosenberg, M (1994) 'Residential Mobility and Migration among Canada's Elderly'. Aging: Canadian Perspectives.

20 Silverstein, M (1995) 'Stability and Change in Temporal Distance between the Elderly and their Children'. Demography, 32 (1) 29-45.

21 Clark, W and White, K (1990) 'Modelling Elderly Mobility'. Environment and Planning A, Vol 22 (7) 909-924.

22 Walters, WH (2002) 'Later-life migration in the United States: a review of recent research', Journal of Planning Literature 17 (1) 37-66.

23 Wiseman, RF (1980)' Why older people move: Theoretical issues'. Research on Aging Vol 2, 141-154.

24 Patrick, C (1980) 'Health and Migration of the Elderly'. Research on Aging Vol 2, 233-241.

25 Fielding, AJ (1992) 'Migration and Social Mobility: South East England as an Escalator Region', Regional Studies, 26 (1) 1-15. 